\title{
Mobile Learning: Moving Past the Myths and Embracing the Opportunities
}

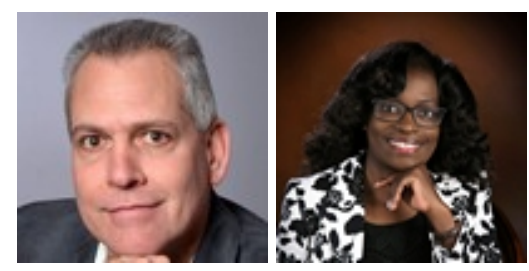

Tom H Brown and Lydia S Mbati University of South Africa

\begin{abstract}
Mobile learning (mLearning) in the open and distance learning landscape, holds promise and provides exciting new opportunities. In order to understand and embrace these opportunities within various contexts and circumstances it is imperative to understand the essence of the phenomenon. In this regard, we first need to understand the core fundamentals of mLearning and gain insight in what mLearning entails.

Using critical reflection, this paper clarifies what mLearning is by invalidating myths and misperceptions related to mLearning. Acknowledging the lessons learnt through past experience, the authors then explore the opportunities that mLearning provides. mLearning challenges and risks are discussed to assist those who are keen to embrace these opportunities, in avoiding unnecessary risks and pitfalls. The paper concludes by sharing a few thoughts on the future of mLearning.

These perspectives on mLearning seek to provide an overview of what mobile learning entails, recognise the achievements of mobile learning to date, and stimulate an appetite to embrace the opportunities in open and distance learning, while minimising the potential negative effects of technological, social and pedagogical change.
\end{abstract}

Keywords: Mobile learning; misperceptions of mobile learning; myths of mobile learning; future of mobile learning; mLearning 


\section{Introduction}

Mobile learning (mLearning) emerged as a new concept towards the end of the previous millennium as educators (teachers/lecturers/practitioners) started exploring the use of mobile technologies in teaching and learning environments. A few pilot projects emerged in the early 2000s, not only in developed countries but also in developing countries and rural settings (UNESCO, 2012a).

Early research and academic discourse focused on defining mLearning as a new emerging discipline. In recent years many projects assisted in the maturation of mLearning and much has already been done to integrate mLearning into mainstream education. However, mLearning is still in its infancy and we are merely seeing the tip of the iceberg.

mLearning holds much promise and provides exciting opportunities for open and distance learning (ODL). In order to understand and embrace the opportunities we first need to understand what mLearning is all about. In the following section, we discuss the myths and misconceptions surrounding mLearning. We follow this with an overview of the pedagogical affordances offered by mLearning, and we provide a synopsis of the challenges mLearning currently faces.

\section{Myths and Misperceptions about mLearning}

A lot has been written to describe and define mLearning. Some authors offer techno-centric definitions of mLearning focussing on the technology and hardware at the exclusion of the learning experience mLearning may offer (Traxler, 2007). When looking at the history of mLearning, Traxler (2009) defines several phases of mLearning conceptions. Initially there was a focus on the mobile technology as such. This changed gradually to a focus on the mobility of the learner and the seamless access to learning support.

Parsons (2014) appropriately used a number of assumptions or misperceptions (myths) in an attempt to describe what mLearning is. We follow suit and, through a critical reflection on the most prominent myths and misperceptions about mLearning, clarify what it is.

\section{mLearning is Learning while Mobile}

This misperception could also be based on the assumption that "mobile" refers to mobility - in other words, learning while "on the move". Interesting in this regard, as pointed out by Parsons (2014), is that we rarely learn while physically moving. He continues by confirming that we tend to take our learning tools with us to the appropriate places. We need to acknowledge though that many learners making use of public transport do in fact participate in mLearning activities while on the move. That is not the misperception though; the misperception lies in the fact that 
mLearning can take place while the learner is static. The learner need not be physically on the move.

\section{mLearning Refers to Learning with Mobile Phones}

Mobile phones are of course not the only type of mobile device that can be used for mLearning. This then does open up the discussion about what types of mobile devices should be regarded as mLearning devices. Some researchers include laptops in their definitions (Corbeil and ValdesCorbeil, 2007), while others feel that a laptop restricts the 'mobility' of a learner and that a mobile device would be those devices that could be operated in a learner's hands (Mellow, 2010 in Crescente and Lee, 2011; Traxler, 2007). In other words, that it should be handheld devices. The important issue here is that the misperception is around mobile 'phones' as the distinctive device for mLearning.

\section{mLearning is all About the Mobile Device}

This is of course a very common misunderstanding and a pitfall that we should always avoid. Technology should always be regarded as the enabler and not as the driver of our teaching and learning activities. The primary purpose of integrating technology into teaching and learning contexts is to enhance the learning experience. Unfortunately, a large body of pilot studies and trials in the use of technology for enhancement of teaching and learning experiences and outcomes are without explicit educational foundations (Kukulska-Hulme et al. in Nouri et al., 2014). The use of technology does not automatically result in effective teaching practices and deep meaningful learning unless effective pedagogical use of the technology is practiced (Ngambi, 2013).

\section{mLearning is Merely eLearning Accessed through Mobile Devices}

mLearning has been defined by some researchers in the field as eLearning using mobile devices (Pinkwert et al., 2003 in Caudill, 2007). Some sceptics refer to mLearning as "e-learning lite" as they believe it can only offer snippets of content (Hlodan, 2010). It has also been defined as a subset of eLearning and/ or as an extension of eLearning (Crescente and Lee, 2011). Although this is true to an extent, Parsons (2014) correctly points out that this view does not take into account any of the additional affordances of the mobile device, for example location awareness and both synchronous and asynchronous collaborative communication.

\section{mLearning is Not Possible in Rural Africa}

It is a common and fair assumption from many first world researchers that mLearning is not really possible in rural settings where low bandwidth restricts the use of bandwidth intensive resources such as video-streaming, multimedia and operating rich applications (Elias, 2011). However, there have been many successful mLearning projects in deep rural settings on some of the most basic mobile phones and other mobile devices. A number of mLearning initiatives have emerged in Africa, for example BridgeIT in Tanzania, MoMath in South Africa and Dunia Moja, a collaborative environmental education project between Stanford University (USA) and three 
universities in Africa (UNESCO, 2012a). A lot has and can be achieved through the creative use of SMS technology (short message service) and WAP (wireless access protocol) on basic mobile phones, especially in distance learning (e.g. Brown, 2004 and 2005).

\section{mLearning is only Applicable to Distance Learning and Not to Face-to- Face Classroom Activities}

It is needless to point out that there are excellent examples of successful mLearning activities taking place in both distance learning and face-to-face classroom environments. In one example, learners can extend their formal face-to-face learning to homework, field trips, and museum visits by reviewing learning material on mobile devices or collecting and analysing information using handheld devices (Sharples, Taylor and Vavoula, 2005). mLearning is very suitable for distance learning, but is most definitely not solely applicable to distance learning.

\section{mLearning means Accessing and Completing all Course Material and Coursework on a Mobile Device}

The misperception here is that it should be "fully/ totally mobile" similarly to the concept of "fully online" in cases of eLearning solely delivered online. The important point we need to understand here is that mLearning opportunities can be small components, activities or events within any mode of delivery. The key would be in the value that the mLearning component adds to the success and quality of the teaching and learning.

\section{mLearning Uses Existing Learning Environment Designs and Current Teaching and Learning Methodologies}

Much has been researched and written about the fact that the transition from face-to-face education to eLearning is not a case of merely converting learning materials to distance learning and electronic format, and making it accessible through the Internet. It is now an accepted "nobrainer" that eLearning provides new and unique affordances to the teaching and learning environment in terms of, for example, resource-rich multimedia learning materials, interactivity and communication. The same goes for mLearning. We cannot merely use our existing eLearning or ODL environment designs and teaching methodologies. It is essential to (re)design our teaching and learning activities to be able to optimise our mLearning environments and to exploit the new and unique affordances that mLearning provides.

In summary, reflecting on all the myths discussed and moving towards a suitable and contemporary definition of mLearning, we would like to echo the words of David Parsons:

To ensure that future mLearning systems meet their full potential, it is necessary that our understanding of mLearning encompasses all of its unique characteristics, and that we recognise that any form of learning that takes pace using a mobile device is mLearning, whether on the move or static,

This work is licensed under a Creative Commons Attribution 4.0 International License. 
whether in formal or informal settings, whether working

collaboratively or alone. (Parsons, in Ally \& Tsinakos, 2014)

We have now cleared some of the most important misunderstandings. Let us now move past these myths and explore the opportunities that mLearning provides for ODL.

\section{Pedagogical Affordances Offered by mLearning}

mLearning is appropriate for designing learning environments for a variety of learning contexts (Crescente and Lee, 2011). In this section, we look at the general affordances that mLearning offers.

\section{Administrative Support and Motivational Messages Through SMS}

Various distance and higher education institutions in Africa pioneered the use of SMS on very basic mobile phones since the early 2000s (Brown, 2004 and 2005; Mostert, 2010; Naidoo, 2011; UNESCO, 2012b). It is a very simple but very powerful tool to communicate easily and just-intime with large groups of learners or even individually. Many institutions are still using bulk SMS as a regular communication tool for learners, not just in rural settings for distance learners, but also on residential campuses. SMS technologies have now been fully integrated in most learning management systems.

\section{Quizzes on Very Basic Phones}

Many case studies have been reported during the past decade where multiple-choice questions (MCQs) have been implemented in mLearning environments for use on basic mobile phones. In most cases, learners answer each question by merely typing the letter or number and replying to the SMS they have received with the MCQs. There are some examples of more sophisticated and automated SMS response systems and USSD (Unstructured Supplementary Service Data) systems operable on basic mobile phones. USSD is often used for location-based content services and menu-based information services.

Quizzes have proved effective in teaching and learning when used as a learning enhancement strategy. Random quizzes may encourage learners to study more, to be continuously engaged with the material, to experience less test anxiety, and probably score higher on standardized tests (Roediger and Karpicke, 2006).

\section{Audio-Visual Affordances}

Smartphones and tablets have become powerful devices due to their rich and user-friendly audiovisual functionalities. These mobile devices can capture and display high resolution images, record and play reasonable quality audio and video, share these items with friends via MMS (multimedia messaging service), Bluetooth, NFC (near-field communication), email and instant 
messaging; or publish the items on the Internet and social media. There is almost an abundance of tools, apps and technologies available for educators and learners to make the use of audiovisual materials in their teaching and learning activities.

\section{Audio-Rich Language Learning}

The key to effective language learning lies in listening to and speaking the language pronunciation plays a significant role. Audio recording and playback functionalities on mobile devices make it possible for mobile learners to read a word or sentence aloud while recording it, playing it back to listen to his/her own pronunciation, and compare it to the correct audio clip provided by the language learning programme. This is very helpful for oral practice and to reduce anxiety amongst second language speakers (Huang and Hung, 2010). Voice recordings allow listeners to replay content as often as they wish and encourage active learning, audio feedback and reflective learning (Ngambi and Donnelly, 2010). The best of all is that the learner carries this learning environment around with him/herself wherever they go, learning a new language anywhere, anytime and at their own pace.

\section{Location Awareness and GPS}

Some of the most popular earlier examples of location-aware and contextual learning applications have been in museums (Lonsdale et al., 2004). Information about museum artefacts is pushed to a learner's mobile device when he or she comes within close proximity of the artefact. Although museum applications remain popular, many contemporary examples of location-aware applications can be found in various cities and urban environments such as shopping malls, airports and of course various travel-related environments. The latest generation of smartphones as well as some tablets are equipped with GPS (global positioning system) functionalities that provide location and time data. The advantages of location-awareness are that relevant and guiding information can be pushed to a learner's mobile device to provide a personalised, location-based and interactive learning environment. Wood and Romero (2010), for example, report on the use of a GPS enabled learning application. The application, known as MoveGrapher, allows physics learners to understand kinematic graphs by generating and displaying distance and speed time-graphs of their own motion whilst walking and running.

\section{Contextual and Situated Learning}

Developments in contextual learning environments link mobile apps to the current context of the learner (e.g. location, direction, activity, surroundings and time) and allow the learner to record the contextual activities and interact with the surroundings. Context-aware technologies make it possible to augment the learner's environment with relevant and supportive information and services. Fieldwork provides a very good practical example of contextual and situated learning. Mobile apps can be combined and integrated with cloud-based services and multiplatform applications to enable cross-context and performance-support learning (Wong and Looi, 2011).

This work is licensed under a Creative Commons Attribution 4.0 International License. 


\section{Simulations and Serious Games}

Simulations are very powerful resources to teach and learn complex, technical and even abstract concepts. Serious games take it a step or two further and provide opportunities to engage learners in meaningful and exciting as well as competitive educational activities. Serious games employ pedagogy to infuse instruction into the game play experience (Greitzer, Kuchar and Huston, 2007 in Tsekleves et al., 2014). Further, Tsekleves et al. (2014) make a distinction between game based learning and serious games as the former includes a wider variety of game platforms whereas serious games employ primarily video game technology platforms, console games, online games and mobile games.

Serious games can be used to facilitate collaborative and problem based learning while increasing learner motivation and performance (Burguillo, 2010). Motivation of learners corresponds to a set of physiological processes that influence the direction, vigour and persistence of behaviour (Moos and Marroquin, 2010). Simulations allow for the development of a range of higher order and psychomotor skills in a virtual environment. Connolly et al. (2012) carried out a systematic literature review investigating the potential positive impacts of gaming with respect to learning, skills enhancement and engagement. The review found that the most frequent occurring impacts of serious games were knowledge acquisition, affective and motivational outcomes.

\section{Augmented Reality and Immersive Presence}

Augmented reality refers to applications where digital objects are related to physical objects (Specht, Ternier \& Greller, 2011). Fitzgerald et al. (2012) considers a working definition of augmented reality to include the fusion of any digital information within real world settings, i.e. being able to augment one's immediate surroundings with electronic data or information, in a variety of media formats that include not only visual or graphic media but also text, audio, video and haptic overlays.

Augmented reality is an effective means to allow learners to explore and experience digital objects in a real life environment as if the digital objects were real life physical objects. The built-in camera of mobile devices can be used to trigger interactive 3D models. Digital information triggered by geo-location data through a smartphone or tablet's GPS, can be 'overlayed' onto the real world.

Emerging multi-user virtual environments allow learners to actively engage in experiences with the avatars of other participants providing interactive and collaborative experiences with digital objects and tools, such as historical photographs and virtual microscopes, and allowing virtual gestures (Dunleavy, Dede and Mitchell, 2008).

Immersive presence is related to augmented reality in that humans 'immerse' themselves in virtual environments where they can interact with other humans through virtual interaction with digital images in 3D as if the other human(s) were physically present, although they are in fact not

This work is licensed under a Creative Commons Attribution 4.0 International License. 
present. The virtual interaction is synchronous. In this way augmented reality can be used to stimulate collaborative and interactive learning.

The possibilities and benefits of mobile augmented reality have been flagged for several years (J ohnson, Levine and Smith 2009; Cook 2010), but have unfortunately not become mainstream yet due to various understandable reasons, for example, the skills required for the development of mobile augmented reality applications and the costs involved. However, a number of open-source and free augmented reality software and applications are becoming available and will assist in mainstreaming augmented reality into ODL.

\section{Integrating Formal and Informal Learning}

Considerable learning occurs outside of the formal classroom and institutionalised distance learning settings through learners personalising and structuring their learning processes and environments. Learning is interwoven with everyday activities that take place in everyday locations. These impromptu learning spaces include workplaces, outdoors, places of leisure and cafes (Sharples, Taylor and Vavoula, 2005). This is in contrast to strictly formal learning which is seen as learning occurring exclusively within the confines of the classroom setting. The ideal learning environment would integrate both formal and informal learning processes.

\section{Personalised Learning and Personal Learning Environments}

mLearning allows learners to personalise their learning based on their characteristics and preferences, as well as the tools and applications available to them without time and space limitations. The learner thus builds and develops his/her own choice of educational activity through the use of web-based applications and social media to create personal and authentic communities of learning. Sampson and Karagiannidis (2002) characterize personal learning environments as one-to-one or many-to-one learning contexts (i.e. one or many tutors for one learner); learning independent of time, space and location; and learning designed around learners' characteristics.

\section{Personal Publishing and Sharing}

Social media and related applications allow for user-friendly and instant personal publishing and sharing of all types of media (text, images, audio, video). Content creation and the personal publishing of content has become part of the daily lives of learners. Being able to publish effortlessly from mobile devices has now made it possible to do personal publishing and sharing from anywhere, anytime.

The sophistication of contemporary mobile devices provides such a wealth of affordances to distance and mobile learners. Being able to measure, analyse, capture, publish, organise, evaluate and communicate is so powerful for learning. It has brought a whole new dimension to learning. And this wealth of learning tools is now truly in the palm of your hand and at your fingertips.

This work is licensed under a Creative Commons Attribution 4.0 International License. 


\section{Emerging Pedagogies for mLearning}

A number of new pedagogies have emerged in recent years tailored to meet the needs of the $21^{\text {st }}$ century learner. These pedagogies are undoubtedly influenced by but also support the nature of mLearning affordances and the nature of today's society.

\section{Social Constructivism}

Constructivism refers to learning as the construction of new meanings (knowledge) by the learner $\mathrm{him} /$ herself. Social constructivism refers to learning as the result of the active participation in a 'community' where new meanings are co-constructed by the learner and his/ her 'community', and knowledge is the result of consensus (Gruender, 1996; Savery and Duffy, 1995 in Brown, 2006).

Tsipurksy (2013) coined the term "class-sourcing" as his adaptation of the term "crowd-sourcing". He describes it as a teaching strategy that can help researchers and educators to reach their learners while being relevant in a digital age. "Class-sourcing involves having faculty members give class assignments where learners make publicly accessible online digital artefacts, such as wikis, websites, blogs, videos, podcasts and others" (Tsipurksy, 2013). Learners then report on topics relevant to their class in a visually appealing fashion. The learners conduct independent research on a specific topic they choose, analyse the information they find, and organize and communicate this data. These activities strengthen research skills as well as critical thinking, while providing opportunities to do their own informal "publishing".

\section{Heutagogy}

Heutagogy is characterised by its potential to create new knowledge required in the current changing interconnected world. As a learning theory, heutagogy is an extension of andragogy and borrows heavily from complexity, systems and constructivism theories. However, the defining characteristic that sets heutagogy apart is the highly learner-centred approach it adopts (Hase and Kenyon, 2000 in Canning and Callan, 2010). In the heutagogical world, the learner shares content and resources in a self-determined manner (Ashton and Newman, 2006). In addition, self-efficacy in heutagogical learners increases when the learners experience positive emotional satisfaction from the learning experience.

\section{Complexity Theory}

Complexity theory arose in a particular context within the natural sciences (Morrison, 2002 in Morrison, 2006). This paradigm was concerned with discreet elements acting upon each other in self-enclosed systems. It rejects the reductionist view that a complex whole can be broken down into its constituent parts and understood in its entirety. This reductionist view could be used to explain the workings of whole systems as no more than the sum of their parts. Complexity theory is sensitive to systemic properties and relationships which are emergent arising from interactions of the parts over time (Morrison, 2006). The whole is thus said to be greater than the sum of its parts and thus the dissection of its constituent parts destroys the system and precludes a full

This work is licensed under a Creative Commons Attribution 4.0 International License. 
understanding of its dynamics and properties. If learning is seen as a complex system, mLearning lends itself well to the various systemic dynamics that feed the learning process.

\section{Rhizomatic Learning}

Rhizomatic learning views ideas as multiple, interconnected, self-replicating and having no beginning and end. This belief system calls for educational models that allow for the fluidity of knowledge conception, in a world where cutting edge knowledge becomes obsolete due to the ephemeral nature of the Web (Cormier, 2011). In the rhizomatic model of learning, curriculum is constructed and negotiated in real time by the contributions of those engaged in the learning process (Cormier, 2008). In this regard, learning is seen as a dynamic process which allows all players in the learning process to actively contribute to it.

\section{Connectivism}

On explaining connectivism as a learning paradigm, Downes (2010) says it is "the thesis that knowledge is distributed across a network of connections, and therefore that learning consists of the ability to construct and traverse those networks". In further explaining connectivism, Siemens (2005) clarifies that connectivism integrates principals of chaos, network, complexity and self-organising theories. Siemens (2005) continues with his description of connectivism by saying that the learning process "...is focused on connecting specialized information sets, and the connections that enable us to learn more are more important than our current state of knowing." He also states:

connectivism is driven by the understanding that decisions are based on rapidly altering foundations. New information is continually being acquired. The ability to draw distinctions between important and unimportant information is vital. The ability to recognize when new information alters the landscape based on decisions made yesterday is also critical.

\section{Navigationism}

Navigationism is a learning paradigm in which learners find, identify, manipulate and evaluate information and knowledge. This knowledge is integrated in their world of work and life to solve problems and to communicate this knowledge to others. Navigationism allows learners to navigate within the enormous information explosion (Brown, 2006). In further explaining navigationism, Brown emphasizes that successful learning takes place when learners solve contextual real life problems through active engagement in problem-solving activities and extensive networking, communication and collaboration. The aim of these activities is not to gain or create knowledge, but to solve problems. Knowledge is, of course, being created in the process, but knowledge creation is not the focus of the activities per se. In a navigationist paradigm, the role of the educator is to coach the learners in HOW to navigate - to be their mentor in the navigating skills and competencies required in the knowledge era. The educator becomes the

This work is licensed under a Creative Commons Attribution 4.0 International License. 
"coach in touch". Knowledge navigation is the central issue of what teaching and learning is about and the focus of learning is on "navigating" in the ocean of available knowledge (Brown, 2006).

\section{Challenges to the Implementation and Sustainability of mLearning}

While the opportunities that mLearning offers are immense, there are some challenges that need to be addressed to allow mLearning to advance in practice. In this section, we look at some of the challenges that may impede the widespread adoption of mLearning.

\section{Resource-Rich mLearning for Rural Learners}

While the rapid growth of wireless infrastructure through-out developing countries provides mobile connectivity to more and more people each year, even in rural settings, the majority of wireless connectivity is still in the low bandwidth of GSM and basic GPRS bands. This means that while mobile learners do have access to voice and data, low bandwidth restricts the use of resource-rich materials such as video-clips, audio and video streaming, and downloading large files. Additionally, the majority of mobile devices in rural environments are still very basic mobile phones. The uptake of smartphones and tablets is still very low, not only due to the lack of the bandwidth provision of the wireless infrastructures, but also due to the fact that the poorer communities cannot afford the more expensive devices.

\section{Connectivity Costs and Data Costs}

Due to financial constraints the majority of mobile users in developing countries do not qualify and cannot afford fixed monthly contracts for voice and data services. They make use of "prepaid" services to gain on-demand mobile connectivity and services. Service providers across the world, but especially in Africa, have expensive rates for data for prepaid clients. The cost of Internet access in low-income countries (many of which are in Africa), relative to income, is 150 times the cost of a comparable service in a high-income country (Odongo, 2010). It is very expensive for mobile learners from lower income communities to sustain connectivity. While mobile devices are constantly evolving, mLearning is driven by access to affordable and reliable connectivity.

\section{Smart Device Ownership}

In many rural contexts, learners share smartphones or tablets with other learners and with their families due to the fact that a community or family/ household can only afford one such expensive device. It has to be shared amongst all members of the family.]

mLearning is reliant upon the ubiquity of the mobile device. As mLearning takes place regardless of time and space, the learner ought to have the mobile device with him/ her in order for both 
formal and informal learning to occur within various contexts at various times. Sharing a mobile device inhibits mLearning. Individual ownership of the mobile device facilitates personalised learning activities.

\section{Digital Literacy}

Digital literacy of both learners and educators remains a challenge. In fact, many learners are in recent days more digital literate than most educators, especially when it comes to mobile technologies and social media. Some of the reasons for lack of digital literacy amongst educators include insufficient professional development due to lack of funding, the paucity of digital literacy agendas, ambiguity around the definition of digital literacy and the required attitude shift on the part of educators (J ohnson et al., 2014).

\section{Bring Your Own Device (BYOD) and Associated Technical Support}

BYOD is the way things are rapidly moving. While it offers the benefits of flexibility and familiarity on the part of the device owner, it also provides challenges in terms of connectivity for a wide range of possible devices and operating systems. BYOD requires increased IT resources and IT systems managers report a proliferation of system security risks associated with BYOD, such as viruses (Barker, 2014). To mitigate some of these challenges, institutions may opt for choosing your own device out of approved devices, or corporate owned personally-enabled devices (Henderson, 2014). In addition, recommendations are made for the placing of BYOD traffic on a dedicated virtual network separate from the institutional network as a means to decreasing security risks (Rath, 2012).

Despite these challenges and concerns about security risks and technical support, networking environments have developed and evolved to such an extent over the past few years that many of these concerns have been addressed. However, the remaining technical challenge relates to the complexity of support and maintenance required in environments where mass deployment of eBooks and course materials requires specialised software applications to run on all devices for all learners at a specific institution. Maintenance and support in such environments are costeffective, minimised and simplified when an institution opts to provide only one selected mobile device, running on one operating system, and all users use exactly the same software applications for teaching and learning. Nevertheless, future developments in terms of operating systems, technology (hardware) and software will eliminate these concerns and allow for seamless operation regardless of device and operating system.

\section{Software Enabling Seamless Ubiquitous Learning}

Recent developments in wireless and sensor technologies has made it possible to develop contextaware ubiquitous learning environments that are able to sense the situatedness of learners and provide adaptable support according to the situatedness and personal preferences of learners. There are already several levels of individualized guidance which can be provided in contextaware ubiquitous learning environments: for naive learners, adaptive supports and guidance for real-world operations or observations can be provided; however, for experienced learners with 
different backgrounds and experiences, only hints or necessary warnings are given (Hwang et al., 2008).

Nevertheless, while many researchers have been investigating the development of such learning environments, software and systems development for context-aware ubiquitous learning environments have not yet been fully achieved. The expense of creating context-aware ubiquitous learning systems is also still very high.

\section{The Content-Driven Paradigm}

A content-driven approach to education is characterized by curriculation and educational activities that focus on subject content. The emphasis is on the content that learners should master and a learner receives a qualification based on the nature, amount and level (difficulty) of subject content he/ she has mastered. In contrast, an outcomes-based approach to education focuses on the learning outcomes to be achieved by the learners. A typical process for curriculation in an outcomes-based model is characterized by the formulation and selection of learning outcomes that a learner should achieve. The selection of subject content is in turn based on the relevance thereof to enable the learner to achieve the learning outcomes.

It is worrying to observe and difficult to accept that we, as educators and educationists, are still continuing to work within our "content-driven" paradigms, providing our learners with preselected and carefully designed and developed content. That in an era where there is an abundance of meaningful and accessible information available.

\section{The Future of mLearning}

mLearning has grown exponentially during the past decade and is flourishing in contemporary social constructivist learning environments. However, although mLearning might be thriving at the moment, it is still a long way from maturity. mLearning will continue to grow. Innovative mobile technologies and new mobile tools geared towards accessing and manipulating information will provide new opportunities for mLearning in the future.

Future mLearning environments will provide more opportunities for personalised and contextual learning in pervasive settings. We will see further developments in social-constructivist learning environments with more examples of class-sourced and expert/lecturer reviewed learning resources being made available to mobile and distance learners from anywhere in the world. New mobile and wireless technologies will provide opportunities to create resource-rich learning resources and learning environments. The steep growth of free Wi-Fi infrastructure in public areas, public transport and very soon even in rural settings as access to Wi-Fi infrastructure and satellite technologies will increase rapidly also in developing countries.

This work is licensed under a Creative Commons Attribution 4.0 International License. 
Wearable technologies and bio-technology will become more and more commercially viable and will path the way for the seamless integration of technologies for true ubiquitous learning.

We foresee exponential growth in the use of simulations and augmented reality in mLearning. The possibilities and benefits of mobile augmented reality have not become mainstream yet due to various reasons, for example, the skills required for the development of mobile augmented reality applications and the cost of technologies and devices used in such environments. However, with the number of open-source and free augmented reality software and applications becoming available, the uptake into mainstream will snowball soon. J ust as it has become fairly easy to create eLearning content - which was a strenuous and elite novelty just a few years ago educators will be able to create augmented reality content artefacts almost on the fly.

We will certainly also see more and more comprehensive and complex mLearning apps being developed and available at low or no cost to learners and educators, allowing for rich and complex teaching and learning activities to take place in creative and innovative new learning environments. Similarly, edugaming will win much field and take learning beyond the area of simulations and serious games. The value of and motivational factors embedded in "competition" have an influential impact on learning and contributes significantly to the popularity of using serious games in learning environments.

Technological developments continuously introduce new and alternative views about our interaction with information and people, and about the skills and competencies we require to survive in the knowledge era and in future. Some of the underlying or fundamental skills required are problem solving skills, digital literacy skills, information literacy, visual media literacy, as well as psychological and emotional competence.

In addition to these skills, the following are some examples of the skills and competencies required in a navigationist paradigm and future mLearning environments (Brown, 2006):

- Finding relevant and up-to-date information.

- Contributing meaningfully to the knowledge production process. This includes the mastery of networking skills and skills required to be part of and contribute meaningfully to communities of practice and communities of learning.

- Analysing, synthesising and evaluating connections and patterns.

- Contextualising and integrating information across different forms of information.

- Reconfiguring, re-presenting and effectively communicating information.

- Managing information (identify, analyse, organize, classify, assess, evaluate).

This work is licensed under a Creative Commons Attribution 4.0 International License. 
- Distinguishing between meaningful and irrelevant information for the specific task at hand or problem to be solved.

- Distinguishing between valid alternate views and fundamentally flawed information.

- $\quad$ Sense making and chaos management.

- Information literacy and metaliteracy.

Social media environments are transient, collaborative, and free-flowing, requiring a comprehensive understanding of information to critically evaluate, share, and produce content in multiple forms. Learners apply knowledge gained from a wide range of verbal, print, media, and online sources and continuously refine skills over time (Mackey and J acobson, 2011).

As envisaged by Brown and Duguid (2000), traditional villages and communities as we know them will survive technological advancement but will be adapted to the conditions of a new world saturated with information.

Future mLearning environments will require of learners to be competent in these type of navigating skills to be able to learn effectively.

\section{Conclusion}

The role technology can play in the enhancement of the learning experience cannot be overstated. Mobile phones for example have evolved from slow and bulky devices to smaller, sophisticated and ubiquitous smartphones. Contemporary mobile technologies now include various types and sizes of mobile devices, as well as complex and sophisticated systems, software and applications. These mobile technologies have started to make significant contributions to distance teaching and learning by providing personalised contextual learning experiences.

As with new phenomena, myths and misperceptions exist regarding what mLearning does and does not entail. In order to understand the fundamentals of mLearning, we have defined what mLearning is by addressing the major misperceptions and outlining some of the possibilities that mLearning offers to the enhancement of ODL.

mLearning is evolving as new affordances are becoming possible via mobile technologies. The opportunities offered by mLearning are immense. In order to ensure the promise of mLearning is fully realised, the existing challenges that act as impediments to the adoption of mLearning need to be addressed. We have discussed some of the essential risks, pitfalls and challenges that ODL practitioners should avoid when designing and implementing mLearning.

This work is licensed under a Creative Commons Attribution 4.0 International License. 
The emergence of mLearning has occurred in congruence with the disruption of hierarchical teaching and learning structures. Emergent pedagogical approaches embrace new ways of learning taking into cognisance the characteristics of current and future learning environments, the comparatively easy access to an abundance of information in various modes, and the possibilities of communicating both synchronously and asynchronously with relative ease. The future of mLearning is indeed only limited by our own imagination. 


\section{References}

Ashton, J . \& Newman, L. (2006). An unfinished symphony: 21st century teacher education using knowledge creating heutagogies. British J ournal of Educational Technology, 37(6), 825840.

Barker, C. (2014). BYOD: Why the biggest security worry is the fool within rather than the enemy without. http:// www.zdnet.com/ byod-why-the-biggest-security-worry-is-the-fool-withinrather-than-the-enemy-without-7000035190

Brown, J.S. \& Duguid, P. (2000). The social life of information. http:// firstmonday.org/ ojs/index.php/ fm/article/ view/ 738/647

Brown, TH. (2004) The role of m-learning in the future of e-learning in Africa. In: Distance Education and Technology: Issues and Practice, 197-216, Open University of Hong Kong Press, Hong Kong, China.

Brown, T.H. (2005). Towards a model for m-learning in Africa. International J ournal on Elearning, 4(3), 299-315. Norfolk, Va., Association for the Advancement of Computing in Education (AACE).

Brown, T.H. (2006). Beyond constructivism: Navigationism in the knowledge era. On the Horizon, 14(3), 108-120, Emerald Group Publishing limited, Bradford, United Kingdom.

Burguillo, J .C. (2010). Using game theory and Competition-based Learning to stimulate student motivation and performance. Computers in Education, 55(2), 566-575.

Canning, N. \& Callan, S. (2010). Heutagogy: Spirals of reflection to empower learners in higher education. Reflective Practice, 11(1), 71-82.

Caudill, J G. (2007). The growth of m-Learning and the growth of mobile computing: parallel developments. International Review of Research in Open and Distance Learning, 8(2), Special Issue: Mobile Learning. http:/ / www.irrodl.org/ index.php/irrodl/article/ view/ 348/913

Connolly, T.M., Boyle, E.A., MacArthur, E., Hainey, T. \& Boyle, J .M. (2012). A systematic literature review of empirical evidence on computer games and serious games. Computers \&Education, 59, 661-686.

Cook, J . (2010). Mobile phones as mediating tools within augmented contexts for development. International J ournal of Mobile and Blended Learning, 2(3), 1-12.

This work is licensed under a Creative Commons Attribution 4.0 International License. 
Corbeil, J .R \&Valdes-Corbeil, M.E. (2007). Are you ready for mLearning? Educause Quarterly, 2, 51-58. http:// www.educause.edu/ero/article/are-you-ready-mobile-learning

Cormier, D. (2008). Rhizomatic education : Community as curriculum http:// davecormier.com/ edblog/2008/06/03/rhizomatic-education-community-ascurriculum

Cormier, D. (2011). Rhizomatic learning: Why we teach? http:// davecormier.com/ edblog/ 2011/ 11/ 05/ rhizomatic-learning-why-learn

Crescente, M \& Lee, D. (2011). Critical issues of m-learning: design models, adoption processes and future trends. J ournal of the Chinese Institute of Industrial Engineers, 28(2), 111123. doi:10.1080/10170669.2010.548856

Downes, S. (2010). Personal learning environments and the PLENK online course. http:// www.slideshare.net/ Downes/ personal-learning-environments-and-plenk2010

Dunleavy, M. Dede, C. \& Mitchell, R. (2008). Affordances and limitations of Immersive Participatory Augmented Reality Simulations for Teaching and Learning. J ournal of Science Education and Technology, 17(2), 138-151.

Elias, T. (2011). Universal instructional design principles for mLearning. The International Review of Research in Open and Distance Learning, 12(2). http:// www.irrodl.org/ index.php/irrodl/article/view/ 965/ 179

FitzGerald, E., Adams, A., Ferguson, R., Gaved, M., Mor, Y. \& Thomas, R. (2012). Augmented reality and mLearning: The state of the art. International J ournal of Mobile and Blended Learning, 5(4), 43-58.

Henderson, J . (2014). Top 3 challenges of BYOD for management and ICT teams. http:// www.computerworld.co.nz/article/558595/three-main-challenges-byodmanagement-ict-teams/

Hlodan, O. (2010). Mobile Learning anytime anywhere. BioScience, 60(9), 682-682.

Huang, H-T. D. \& Hung, S-T. A. (2010). Implementing electronic speaking portfolios: Perceptions of ELF students. British J ournal of Educational Technology, 41(5), E84-E88.

Hwang, G.-J., Tsai, C.-C., \& Yang, S. J . H. (2008). Criteria, strategies and research issues of context-aware ubiquitous learning. Educational Technology \& Society, 11(2), 81-91.

J ohnson, L., Adams Becker, S., Estrada, V. \& Freeman, A. (2014). NMC Horizon Report: 2014 Higher Education Edition. Austin, Texas: The New Media Consortium.

This work is licensed under a Creative Commons Attribution 4.0 International License. 
Johnson, L., Levine, A. \& Smith, R. (2009) The Horizon Report: 2009 Edition, Austin, TX.: New Media Consortium.

Lonsdale, P, Baber, C, Sharples, M, Byrne, W, Arvanitis, T, Brundell, P and Beale, H (2004). Context awareness for MOBIlearn: Creating an engaging learning experience in an art museum. Proceedings of mLearn 2004. Bracciano, Rome

Mackey, T.P., \&T.E. J acobson. (2011). Reframing information literacy as a metaliteracy. College \& Research Libraries, 72(1), 62-78.

Mostert, I. (2010). Incorporating a mobile interface in a blended learning programme for mathematics teachers. Paper delivered at The e-learning Africa 2010 Conference, Lusaka, Zambia. http:// academic.sun.ac.za/ kol/Ingrid\%20Mostert\%20Extended\%20Abstract\%20for\%20 SOTL.pdf

Moos, D.C. \& Marroquin, E. (2010). Multimedia, hypermedia, and hypertext: Motivation considered and reconsidered. Computers in Human Behavior, 26(3), 265-276.

Morrison, K. (2006). Complexity theory and education. APERA conference 2006, Hong Kong.

Naidoo, O. (2011). Nokia moMaths project report. http://www.schoolnet.org.za/reports/ 1108 nokia.pdf

Ngambi, D. (2013). Effective and ineffective uses of emerging technologies: Towards a transformative pedagogical model. British J ournal of Educational Technology, 44(4), 652-661.

Nouri, J , Cerratto-Pargman, T, Rossitto, C \& Ramberg, R. (2014). Learning with or without mobile devices? A comparison of traditional school field trips and inquiry-based mLearning activities. Research and Practice in Technology Enhanced Learning, 9(2), 241-262.

Odongo, J .R.I. (2010). Beneath the bandwidth: Exploring Africa's information divide. Paper delivered at the 11th DIS Annual Conference 2010, 2-3 September 2010, Richardsbay, University of Zululand, South Africa. http://www.lis.uzulu.ac.za/research/conferences/2010/Dis\% 20conference\%202010\%20Ikoja\%20Odongo\%20edited\%20and\%20corrected\%20paper. pdf

Parsons, D. (2014). The future of mobile learning and implications for education and training. In Ally, M. \& Tsinakos, A., Editors, Perspectives on Open And Distance Learning: 
Increasing access through mLearning. Published by the Commonwealth of Learning and Athabasca University, Vancouver, Canada.

Rath, D. (2012). Are you ready for BYOD: Advice from the trenches on how to prepare your wireless network for the Bring-Your-Own-Device movement. T H E J ournal, 39(4), 2832.

Roediger, H.L. \& Karpicke, J.D. (2006). The power of testing memory: Basic research and implications for educational practice. Perspectives on Psychological Science, 1, 181-210.

Sampson, D. \& Karagiannidis, C. (2002). Personalised learning: Educational, technological and standardisation perspective. Interactive Educational Multimedia, 4, 24-39.

Sharples, M., Taylor, J . \& Vavoula, G. (2005). Towards a theory of mobile learning. http:// www.mlearn.org/ mlearn2005/CD/papers/Sharples\%20Theory\%20of\%20Mobile.pdf

Siemens, G. (2005). Connectivism: A learning theory for the digital age. http:// www.itdl.org/journal/jan_05/article01.htm

Specht, M., Ternier, S., \&Greller, W. (2011). Mobile augmented reality for learning: A case study. J ournal of the Research Center for Educational Technology, 7(1). Retrieved from www.rcetj.org/index.php/rcetj/article/view/ 151

Traxler, J . (2009). Current state of mLearning. In M. Ally (Ed.), mLearning: Transforming the delivery of education and training. Edmonton, AB: Athabasca University Press.

Traxler, J . (2007). Defining, discussing and evaluating mLearning: The moving finger writes and having writ.... International Review of Research in Open and Distance Learning, 8(2). http:// www.irrodl.org/index.php/irrodl/article/view/346/ 882

Tsekleves, E., Cosmas, J . \&Aggoun, A. (2014). Benefits, barriers and guideline recommendations for the implementation of serious games in education for stakeholders and policymakers. British J ournal of Educational Technology. doi:10.1111/ bjet.12223

Tsipursky, G. (2013). Class-sourcing as a Teaching Strategy. Inside Higher Ed, 18 October, 2013. http:// www.insidehighered.com/advice/2013/10/18/ class-sourcing-teaching-strategyessay

UNESCO (2012a). Turning on mLearning in Africa and the Middle East: Illustrative initiatives and policy implications. http:// unesdoc.unesco.org/ images/ 0021/002163/216359e.pdf

This work is licensed under a Creative Commons Attribution 4.0 International License. 
UNESCO (2012b). mLearning for teachers in Africa and the Middle East: Exploring the potential of mobile technologies to support teachers and improve practice. http:// unesdoc.unesco.org/images/ 0021/ 002163/216358e.pdf

Wong, L.-H., \&Looi, C.-K. (2011). What seams do we remove in mobile assisted seamless learning? A critical review of the literature. Computers \& Education, 57(4), 2364- 2381. doi:10.1016/j.compedu.2011.06.007

Wood, S. \& Romero, P. (2010). Learner centred design for a hybrid interaction application. Educational Technology and Society, 13(3), 43-54.

(C) Brown and Mbati

\section{Athabasca University $\mathbf{a}$}

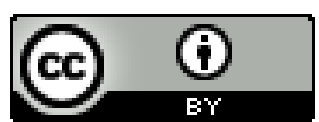

